\title{
Beneficial Neuro-Pharmacological Effect of Passionflower (Passiflora Incarnate L)
}

\author{
Hayder M Al-kuraishy ${ }^{1 *}$, Salah Al-windy² and Ali I Al-Gareeb ${ }^{1}$ \\ ${ }^{1}$ Department Of Pharmacology, Toxicology and Medicine College of Medicine Al-Mustansiriya University, Iraq \\ ${ }^{2}$ Department of medical microbiology, College of science, Baghdad University, Iraq
}

*Corresponding author: Hayder M Al-kuraishy, Department of Pharmacology, Toxicology and Medicine College of Medicine Al-

Mustansiriya University, Iraq

\begin{abstract}
Background: The Passiflora incarnata plant, belonging to the Passifloraceae family and commonly known as passion fruit, is widespread in tropical areas around the world and used in traditional medicine for the treatment of anxiety, nervousness, and neuralgia.

Methods: Evidences from experimental, preclinical and clinical studies are evaluated for bidirectional relationships between Passiflora incarnata and neuropharmacological effects are discussed and opportunities for elaborating these models briefly alluded to. Given the nature of the subject area, it remains clear that this literature search cannot be regarded as mini review. A multiplicity of search strategies took on and assumed which included electronic database searches of Medline and PubMed using MeSH terms, keywords and title words during the search.
\end{abstract}

Conclusion: Passiflora incarnate is effective herbal medicine for anxiety, depression, sleep disorders and various types of addictions.

Keywords: Passiflora incarnate; anxiety; depression; sleep disorders; addictions

\section{Introduction}

The Passiflora incarnata plant, belonging to the Passifloraceae family and commonly known as passion fruit, is widespread in tropical areas around the world and used in traditional medicine for the treatment of anxiety, nervousness, and neuralgia [1]. The genus Passiflora consists of 500 species that are mostly found in warm and tropical regions. Passiflora comes from Latin word "Passio" that was first time discovered by Spanish discoverers in 1529 and was described as a symbol for "Passion of Christ. Passiflora contains several compounds including alkaloids, phenols, glycosyl flavonoids and cyanogenic compounds. In some experiments, it has potential effects for treatment of some diseases like anxiety, opiates withdrawal, insomnia, attention deficit hyperactivity disorder and cancer [2].

\section{Active constituents}

The main chemical constituents of the Passionflower are the flavonoids $(0.25 \%)$ such as vitexin, isovitexin, orientin, isoorientin, apigenin, kaempferol and quercetin. The indole alkaloids $(0.1 \%)$ based on the beta-carboline ring system such as harman, harmin, harmalin, harmol and harmalol. Some other isolated plant constituents have been identified such as glycosides, carbohydrates, amino acids, benzopyrones, cyanogenic glycosides such as gyanocardin, pyrone derivatives such as maltol and ethyl maltol. Two important constituents like chrysin and tri-substituted Benzoflavone Moiety (BZF) have been isolated [3] (Figure 1).

\section{Clinical Uses}

\section{Addiction and dependence}

A BZF moiety has been reported recently to be responsible for the multifarious CNS effects of P. incarnata Linn. In the light of the established usefulness of the BZF moiety in counteracting the withdrawal effects of substances like cannabinoids and nicotine, the bioactive BZF moiety has been tested in mice treated with an addictive dose of ethyl alcohol, in order to evaluate its effectiveness in countering alcohol dependence [4]. It has been reported that 
the BZF of $P$. incarnata, when administered concurrently with cannabinoids, prevented the development of tolerance and dependence of cannabinoids in mice. Even an acute administration of the BZF significantly blocked the expression of withdrawal effects in cannabinoid dependence. So, these studies suggested that the BZF may have beneficial role in cannabinoids reversal [5]. The chronic administration of P. incarnata with alcohol had better preventive effects than the single acute treatment with $P$. incarnata in alcohol-dependent mice. These results suggested that the treatment of $P$. incarnata extract could be used as safe and alternative drug for alcohol withdrawal [6].

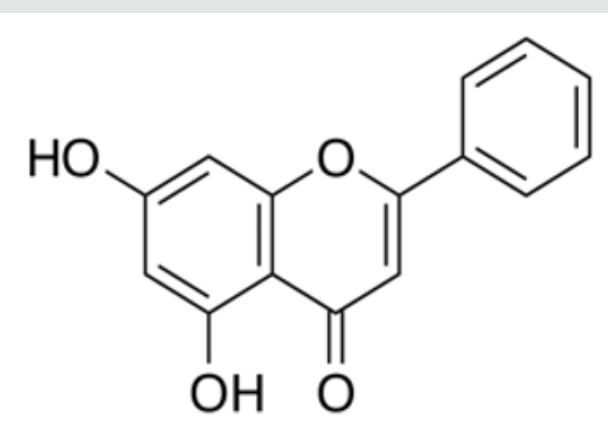

(A)

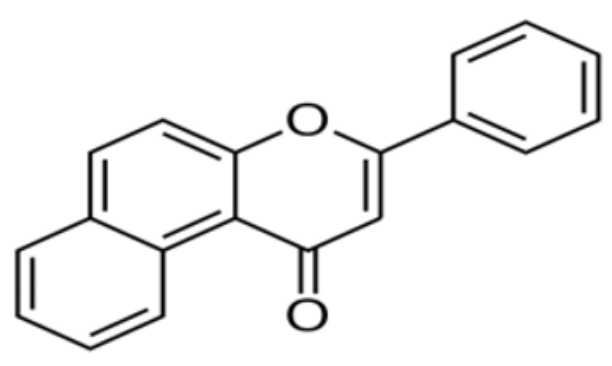

(B)

Figure 1: Active constituents of P. incarnate, (A): Chrysin, (B): Benzoflavone.

Some of the pharmacological studies on the BZF moiety also confirmed that the BZF moiety isolated from P. incarnata was very effective in countering the threat of nicotine addiction in laboratory animals. In light of different reports mentioning the value of $P$. incarnata in tobacco addiction, studies have been performed by using the bioactive BZF moiety isolated from the aerial parts of $P$. incarnata. So, these studies, suggested that the BZF may have value in treating nicotine addiction [7]. The beneficial effect of the cotreatment of diazepam with BZF is therefore apparent, as there are practically very little withdrawal effects even upon chronic intake of diazepam. The BZF moiety of P. incarnata affords a useful anxiolytic agent being free from dependence-liabilities even on a long-term chronic use. The concurrent administration of BZF and diazepam give a useful combination therapy, as the BZF moiety also prevents the development of diazepam-dependence and the subsequent appearance of withdrawal effects. The BZF moiety from passionflower offers a very valuable moiety in countering the hazard of substance dependence [8].

\section{Anticonvulsant activity}

The current therapeutic treatment of epilepsy with modern Antiepileptic Drugs (AEDs) is associated with side effects, dose-related and chronic toxicity and teratogenic effects, and approximately $30 \%$ of the patients continue to have seizures with current AEDs therapy [9]. Natural products from folk remedies have contributed considerably in the detection of contemporary drugs and can be a substitute source for the discovery of AEDs with novel structures and superior safety and efficacy profiles. Verification for anticonvulsant activity of $P$. incarnata in the clonic seizure of the pentylenetetrazols model has been tested. As the protective effects of $P$. incarnata in clonic seizure, it suggests that it could be valuable for treatment of absent seizure. In addition, the significant role of benzodiazepine receptor in the effects of $P$. incarnata should be considered [10].

The anticonvulsant effect of hydroethanolic and aqueous extract of $P$. incarnata may be justified based on the new reports of attendance of $\gamma$-amino butyric acid (GABA; an inhibitory amino acid), which is newly been identified as dominant amino acid in these types of extracts of $P$. incarnata. In cold extraction, maximum amount of GABA was extracted using $44 \%$ ethanol, suggesting that the anticonvulsant effect of $P$. incarnata may be due to GABA. Therefore, based on above discussion it can be concluded that chrysin may not be the active phytoconstituent responsible for anticonvulsant effect of $P$. incarnata. But improved formulations of the methanolic extract with better bioavailability of chrysin can enhance the clinical usefulness of $P$. incarnate [11].

Moreover, Singh et al., found that the hydroethanolic extract of Passiflora incarnata suppress PTZ-induced seizures, and ameliorates its associated post-ictal depression, which has been found to be get worsened with the standard antiepileptic drug, diazepam [12].

\section{Anxiolytic and anti-depressant effect}

$P$. incarnata has been used to cure anxiety and insomnia. A fraction derived from the methanol extract of P. incarnata has been observed to show significant anxiolytic activity in mice using elevated plus-maze (EPM) model of anxiety. The likelihood of a Phyto-constituent having BZF nucleus as the basic moiety being accountable for the bioactivity of P. incarnata is highly anticipated [13]. The possible anxiolytic effects of chrysin are through modulation of the benzodiazepine receptor on the GABA (A) receptor in laboratory rats have been tested. It has been assumed that chrysin decrease anxiety through interaction with the GABA (A) receptor in laboratory rats as measured by elevated plusmaze, corticosterone and catecholamine assays [14]. Also, chrysin may have anxiolytic properties comparable to midazolam but to a slighter scale at the $2 \mathrm{mg} / \mathrm{kg}$ dose used in this study [15]. 
In addition, Chrysin, belonging to the flavone class, is one of the most important bioactive constituents of different fruits, vegetables and even mushrooms. As well, Chrysin possesses powerful neuroprotective effects and inhibits neuroinflammation. As well, chrysin advances cognitive decline and possesses a strong antiamyloidogenic and neurotrophic effects. Furthermore, beneficial effects of chrysin on both depression and epilepsy have been reported [16]. Bortolotto et al, illustrated that reduced levels of 5HT and dopamine in the prefrontal cortex and the hippocampus were observed in the hypothyroid mice than in the euthyroid mice. Chrysin treatment recovered 5HT content in both structures and dopamine content only in the hippocampus. Noradrenaline content was not altered by treatments. Therefore, chrysin treatment reverses depressive-like behaviors in hypothyroid female mice and proposing the involvement of 5HT and dopamine in these effects [17].

Besides, chrysin treatment $(20 \mathrm{mg} / \mathrm{kg})$ resulted in the up regulation of brain derived neurotrophic factor (BDNF) levels which plays a role in the antidepressant action. Thus, chrysin is similar to fluoxetine, is capable of promoting the attenuation of depressant-like behavior and hippocampal dysfunction in mice. These results reinforced the potential of chrysin for the treatment or supplementary treatment of depression, as well as chrysin is also effective therapy in a model of agitated depression [18].

Hypnotic effects have also been reported for Passiflora incarnata $L$. It has been described that numerous pharmacological effects of Passiflora incarnata are mediated via modulation of the GABA system including affinity to GABA-A and GABA-B receptors, and effects on GABA uptake [19]. It is very likely that binding to the GABA-site of the GABA-A receptor is one of the clinically applicable modes of action of Passiflora incarnata extract, because pre-administration of flumazenil (Ro 15-1788), an antagonist of the benzodiazepine binding site of the GABA-A receptor, attenuates the effects of Passiflora incarnata in vivo. Another possible target might be the binding of Passiflora incarnata extract to the GABA-B receptor. There is accumulating evidence that modulators of the GABA-B receptor might act as an anxiolytic, although the compounds responsible for the hypnotic activity of Passiflora incarnata are yet to be identified. However, it is probable that the hypnotic activity could be exerted by the flavonoids chrysin and/ or homoorientin, orientin, vitexin, and isovitexin [20].

\section{Passiflora incarnate and degenerative brain diseases}

Neurodegenerative disorders are a miscellaneous group of diseases of the nervous system. Neurodegenerative dementias and movement disorders are attractive more frequent mostly as a result of augmented life anticipation and changing population demographics [21]. Alzheimer's Disease (AD) is a progressive neurodegenerative disorder distinguished by neuronal degeneration and cognitive worsening, particularly in the elderly
[22]. Parkinson's Disease (PD) is a neurodegenerative disorder characterized by tremors, akinesia, muscle rigidity, and postural instability. Moreover, free radicals are produced close by within the basal ganglia and lead to progressive neuronal injure of substantia nigra neurons in vulnerable individuals. Oxidative stress has been concerned in the pathogenesis of AD and PD through augmented neuronal lipid peroxidation [23]. Harmine and harmaline alkaloids are accounted to be effectual anti-parkinsonism agents. For this reason; antioxidants effect of $P$. incarnata have anti-parkinsonian and memory enhancing activity [24]. Oxidative stress has long been thought to take part in a major role in the pathogenesis of AD. Certain plant products and diet rich in antioxidants are said to be neuroprotective and therefore may have a role in improving cognition in aging and neurodegenerative diseases. Consequently, butanolic extract of Passiflora incarnata flowers has neuroprotective effect in neurodegerarive diseases such as Alzheimer's and Parkinson's disease which is mediated throughout its antioxidant potential [25].

\section{Conclusion}

Passiflora incarnate is effective herbal medicine for anxiety, depression, sleep disorders and various types of addictions.

\section{References}

1. Dantas LP, de Oliveira Ribeiro A, de Almeida Souza LM, Groppo FC (2017) Effects of passiflora incarnata and midazolam for control of anxiety in patients undergoing dental extraction. Medicina oral, patologia oral y cirugia buccal 22(1): 95-101.

2. Pérez JO, d Eeckenbrugge GC (2017) Morphological characterization in the genus Passiflora L: An approach to understanding its complex variability. Plant Systematics and Evolution 303(4): 531-558.

3. Rome M, D Eeckenbrugge GC (2017) Delimitation of the series Laurifoliae in the genus Passiflora (Passifloraceae). Phytotaxa 309(3): 245-252.

4. Tiwari S, Singh S, Tripathi S, Kumar S (2015) A pharmacological review: Passiflora species. Asian Journal of Pharmaceutical Research 5(4): 195202.

5. Dhawan K, Kumar S, Sharma A (2002) Reversal of cannabinoids ( $\Delta 9$ THC) by the benzoflavone moiety from methanol extract of Passiflora incarnata Linneaus in mice: a possible therapy for cannabinoid addiction. Journal of pharmacy and pharmacology 54(6): 875-881.

6. Dhawan K, Kumar S, Sharma A (2002) Suppression of alcohol-cessationoriented hyper-anxiety by the benzoflavone moiety of Passiflora incarnata Linneaus in mice. Journal of ethnopharmacology 81(2): 239244.

7. Jamerson BD, Breivogel CS (2017) Treatment of withdrawal symptoms to aid in nicotine use cessation with Passiflora incarnata. Campbell University, USA.

8. Dhawan K, Dhawan S, Chhabra S (2003) Attenuation of benzodiazepine dependence in mice by a tri-substituted benzoflavone moiety of Passiflora incarnata Linneaus: A non-habit-forming anxiolytic. J Pharm Pharm Sci 6(2): 215-222.

9. Brodie MJ (2010) Antiepileptic drug therapy the story so far. Seizure 19(10): 650-655.

10. Shariati Rad S, Nassiri Asl M, Zamansoltani F (2007) Anticonvulsant effects of Pasipay (prepared from passionflower) by PTZ model in the mice. Journal of Medicinal Plants 3(23): 40-45. 
11. Singh B, Mishra A, Goel RK (2011) Anticonvulsant activity of Passiflora incarnata: No role of chrysin. Journal of pharmaceutical negative results 2(2): 51-54.

12. Singh B, Singh D, Goel RK (2012) Dual protective effect of Passiflora incarnata in epilepsy and associated post-ictal depression. Journal of ethnopharmacology 139(1): 273-279.

13. Nassiri Asl M, Shariati Rad S, Zamansoltani F (2007) Anticonvulsant effects of aerial parts of Passiflora incarnata extract in mice: Involvement of benzodiazepine and opioid receptors. BMC complementary and alternative medicine 7(1): 26.

14. Rodríguez Landa JF, Hernández López F, Cueto Escobedo J, Herrera Huerta EV, Rivadeneyra Domínguez E, et al. (2019) (5, 7-dihydroxyflavone) exerts anxiolytic-like effects through GABAA receptors in a surgical menopause model in rats. Biomedicine \& Pharmacotherapy 109: 2387 2395.

15. Jesse CR, Donato F, Giacomeli R, Del Fabbro L, da Silva Antunes M, et al. (2015) Chronic unpredictable mild stress decreases BDNF and NGF levels and $\mathrm{Na}^{+}, \mathrm{K}^{+}$-ATPase activity in the hippocampus and prefrontal cortex of mice: Antidepressant effect of chrysin. Neuroscience 289: $367-$ 380.

16. Nabavi SF, Braidy N, Habtemariam S, Orhan IE, Daglia M, et al. (2015) Neuroprotective effects of chrysin: From chemistry to medicine. Neurochemistry International 90: 224-231.

17. Bortolotto VC, Pinheiro FC, Araujo SM, Poetini MR, Bertolazi BS, et al. (2018) Chrysin reverses the depressive-like behavior induced by hypothyroidism in female mice by regulating hippocampal serotonin and dopamine. European journal of pharmacology 822: 78-84.

18. Souza LC, Antunes MS, Borges Filho C, Del Fabbro L, de Gomes MG, et al. (2015) Flavonoid Chrysin prevents age-related cognitive decline via attenuation of oxidative stress and modulation of BDNF levels in aged mouse brain. Pharmacology Biochemistry and Behavior 134: 22-30.

19. Shinomiya K, Inoue T, Utsu Y, Tokunaga S, Masuoka T, et al. (2005) Hypnotic activities of chamomile and passiflora extracts in sleepdisturbed rats. Biological and Pharmaceutical Bulletin 28(5): 808-810.

20. Lolli LF, Sato CM, Romanini CV, Villas-Boas LD, Santos CA, et al. (2007) Possible involvement of GABAA-benzodiazepine receptor in the anxiolytic-like effect induced by Passiflora actinia extracts in mice. Journal of ethnopharmacology 111(2): 308-314.

21. Alkuraishy HM, Al Gareeb AI, Albuhadilly AK (2014) Vinpocetine and pyritinol: A new model for blood rheological modulation in cerebrovascular disorders-a randomized controlled clinical study. BioMed research international.

22. Gaudreault R, Mousseau N (2019) Mitigating Alzheimer's Disease by Natural Polyphenols: A Review. Current Alzheimer research 16(6): 529543.

23. Kim GH, Kim JE, Rhie SJ, Yoon S (2015) The role of oxidative stress in neurodegenerative diseases. Experimental neurobiology 24(4): 325340.

24. Ingale SP, Kasture SB (2014) Antioxidant and antiparkinsonian activity of Passiflora incarnata leaves. Oriental Pharmacy and Experimental Medicine 14(3): 231-236.

25. Vijayalakshmi SA, Bhat P, Chaturvedi A, Bairy KL, Kamath S (2012) Evaluation of the effect of Ferula asafoetida Linn. gum extract on learning and memory in Wistar rats. Indian journal of pharmacology 44(1): 79-82.

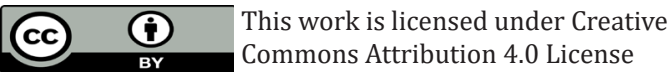

To Submit Your Article Click Here:

Submit Article
DOI: $10.32474 / 0 J N B D .2020 .03 .000172$

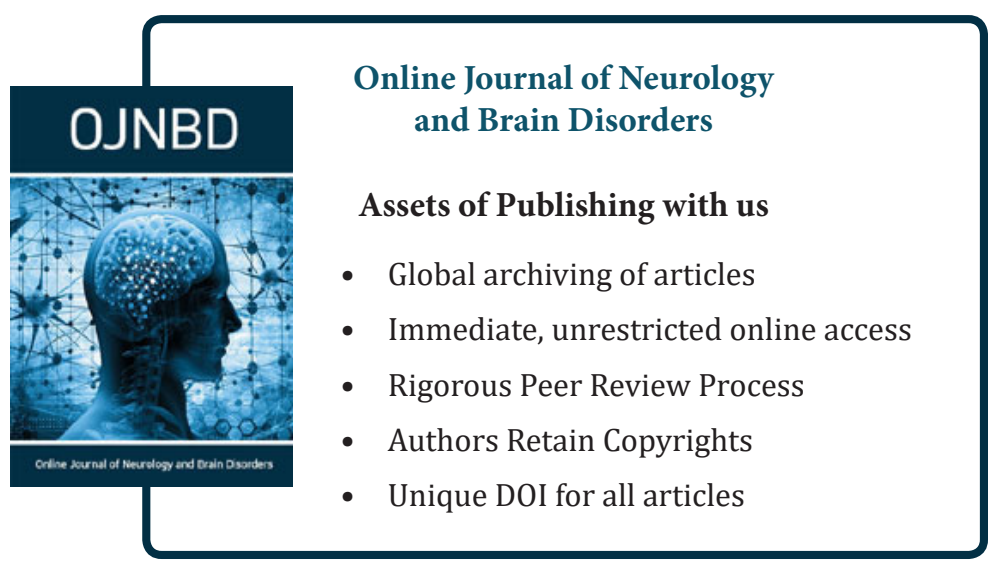

